\title{
Corpo/corporeidade do negro
}

\author{
Body/corporeity of the negro \\ Érika Cristina Silva Alves \\ Mestra em Educação - Universidade Federal do Triângulo Mineiro - UFTM \\ Professora Educação Básica - Secretaria de Estado de Educação de Minas Gerais - SEE/MG. \\ Uberaba, Minas Gerais - Brasil. \\ professoraerikacristina@gmail.com
}

DiDagner Wey Moreira
Doutor em Educação - Universidade Estadual de Campinas - UNICAMP PPGE - Programa de Pós-Graduação em Educação - Universidade Federal do Triângulo Mineiro - UFTM. Bolsa Produtividade Científica em Educação - CNPq. Uberaba, Minas Gerais - Brasil. weymoreira@uol.com.br

O mundo é não aquilo que eu penso, mas aquilo que eu vivo. (Merleau-Ponty, 2011, p. 14)

Resumo: O corpo/corporeidade é a condição do homem; e a radicalização da existência encerra-se no corpo, no movimento em direção ao mundo e outros corpos-sujeitos, através da experiência. Merleau-Ponty (2011) compreende o ser humano pela percepção corporal no mundo sensível. No entanto, por questões construídas ao longo da história, o corpo do negro assumiu uma (des)construção, devido às ações do racismo que dividiu os povos nas sociedades coloniais entre brancos e negros. A estes últimos, formas de tratamento destituíram a humanidade do corpo/corporeidade do negro. Por isso, o objetivo do presente artigo é apresentar a proposta de corpo/corporeidade em Merleau-Ponty, em consonância com o corpo do negro em uma sociedade marcada pela racialização. Diante das discussões, percebe-se uma dialética ao analisar o corpo/corporeidade do negro em uma sociedade edificada no racismo estrutural, pois aquilo que o define enquanto ser, segundo Merleau-Ponty, é o mesmo fator desumanizante - seu corpo.

Palavras chave: corpo/corporeidade; Merleau-Ponty; negro; racialização.

Abstract: The body/corporeity is the human being's condition; and the radicalization of existence is enclosed in the body, in the movement towards the world and other subject-bodies, through experience. Merleau-Ponty (2011) understands the human being through the body perception in the sensitive world. However, due to issues constructed throughout history, the black body has assumed a (dis)construction, on account of the actions of racism that divided people in colonial societies between whites and blacks. To the latter, forms of treatment deprived the humanity of the black body/corporeity. Therefore, the purpose of this paper is to present Merleau-Ponty's proposal of body/corporeity in line with the black body in a society marked by racialization. In light of the discussions, one can see a dialectic when analyzing the black body/corporeity in a society built on structural racism, since what defines it as a being, according to Merleau-Ponty, is the same dehumanizing factor - its body.

Key-words: body/corporeity; Merleau-Ponty; black; racialization.

Cite como

(ABNT NBR 6023:2018)

ALVES, Érika Cristina Silva; MOREIRA, Wagner Wey. Corpo/corporeidade do negro. Dialogia, São Paulo, n. 38, p. 1-14, e20450, maio/ago. 2021. Disponível em: https://doi.org/10.5585/38.2021.20450.

American Psychological Association (APA)

Alves, E. C. S., \& Moreira, W. W. (2021, maio/ago.). Corpo/corporeidade do negro. Dialogia, São Paulo, 38, p. 1-14, e20450.

https://doi.org/10.5585/38.2021.20450. 


\section{Introdução}

Pensar o corpo ao longo da história da humanidade é perceber que ele recebeu inúmeras atribuições e significações de acordo com a época, a cultura, as ideologias e crenças. Sociedades foram edificadas e derrubadas através do uso, instrumentalização, domínio e cerceamento dos corpos. Nesse percurso, o corpo do negro foi apropriado por outros de uma forma distinta, através do racismo em várias nações, e não diferente no Brasil. Fato é que ainda no século XXI percebemos as consequências desses pensamentos e ações de outrora.

Em 1945, Merleau-Ponty fundou uma base teórica acerca do corpo/corporeidade, por meio da obra Fenomenologia da Percepção, trazendo uma abordagem filosófica para a existência sob o prisma da corporeidade. Segundo o autor, somos inscritos no mundo através do nosso corpo; a nossa existência se dá por meio dele. Sentimos o mundo com o corpo e todas as experiências que vivemos passam por ele. As questões do mundo-vida, em todas as suas nuances, nascem e se encerram no corpo/corporeidade, configurando o nosso existir (MEURLEAU-PONTY, 2011).

Em contrapartida, o corpo negro foi interpretado na história como algo diferente, sendo definido por isso como um corpo destituído de direitos, vontades, humanidades. Ser negro numa sociedade racista significa ser corpo para servir, tornando-se um objeto.

De outra forma, o desencontro e a lacuna estão estabelecidos. Se nos comunicamos com o mundo por meio do corpo/corporeidade e as relações estabelecidas por ele e nele, e algumas dessas existências - devido ao racismo - são destituídas daquilo que as define, como ser humano, como é experienciada essa corporeidade?

Analisar a concepção de corpo/corporeidade em Merleau-Ponty, sob o ponto de vista do corpo negro, é o objetivo do presente artigo, bem como refletir a constituição do corpo/corporeidade negro numa sociedade estruturalmente racista, que o nega, o rejeita e o exclui ao longo da história do Brasil. Nessa perspectiva, dialogaremos com Merleau-Ponty (2011), Bosi (1989; 2009), Freyre (2003), Foucault (2008), Kilomba (2019), Almeida (2020), Andre (2007), Nóbrega (2008; 2019) e Mathews (2011).

\section{Corpo/corporeidade em Merleau-Ponty}

Ao pensar na escala dos seres vivos que nascem, crescem, reproduzem-se e morrem, podemos dizer que somos os únicos a ter consciência dessa realidade. Nascemos e sabemos que iremos morrer.

A percepção de si e do mundo modifica toda a nossa relação com ele. A consciência da própria finitude dilata a necessidade de criar sentidos. Ao nascer nos inscrevemos no mundo pelo 
corpo, choramos, rimos, alimentamos, estabelecemos relações com os outros, movimentamos, experimentamos o mundo através da e na corporeidade (MERLEAU-PONTY, 2011).

Merleau-Ponty permite uma nova leitura do mundo, mediada pela corporeidade. Essa visão contradiz a corrente filosófica racionalista da época, na qual o corpo era visto pela ciência apenas como objeto de estudo a ser codificado e analisado pelas partes que o compunha, assumindo um viés cartesiano.

Em sua obra célebre, Fenomenologia da Percepção, o autor analisa com rigor a relação do corpo/corporeidade e as experiências com o mundo, tendo a Fenomenologia como base epistemológica. "Voltar às coisas mesmas" foi o caminho encontrado por Merleau-Ponty para repensar a existência a partir da corporeidade. Em outras palavras, "voltar à pedra basal, à experiência humana direta, pondo de lado quaisquer ideias preconcebidas derivadas de nossas teorias científicas ou de filosofias que se apoiam nessas teorias científicas e tentar dar-lhes um status metafísico" (MATTHEWS, 2011, p. 27).

Nessa premissa, o corpo adquire um novo significado, pois o ser humano passa a ter consciência de si como sujeito corporal, encarnado no mundo, se relacionando com outros sujeitos na mesma condição, compartilhando experiências carregadas de significados e sentidos. Essas percepções não são estabelecidas como regras gerais instituídas pela ciência, mas sim pela percepção do sujeito. "Na concepção fenomenológica da percepção a apreensão do sentido ou dos sentidos se faz pelo corpo, tratando-se de uma expressão criadora, a partir dos diferentes olhares sobre o mundo" (NÓBREGA, 2008, p. 142). Corpo encarnado no mundo demarcado por um tempo e espaço delimitado historicamente, denominado pelo autor como ser-no-mundo (MERLEAU-PONTY, 2011).

Em sua proposta epistemológica, o conhecimento dá-se pela percepção corpórea do sujeito através de sua experiência no mundo. O sujeito é um ser-no-mundo, e só depois disso estabelecerá conceitos (MERLEU-PONTY, 2011). É importante ressaltar que esse pensamento era uma crítica à ideia vigente na época, momento em que se afirmava a separação de sujeito e objeto do conhecimento.

Em Merleau-Ponty, corpo/corporeidade é a via para a existência e é por ele e nele que acontecem todas as experiências do mundo vivido. 


\begin{abstract}
Engajo-me com meu corpo entre as coisas, elas coexistem comigo enquanto sujeito encarnado, e essa vida nas coisas não tem nada de comum com a construção dos objetos científicos. Da mesma maneira, não compreendo os gestos do outro por um ato de interpretação intelectual, a comunicação entre as consciências não está fundada no sentido comum de suas experiências, mesmo porque ela o funda: é preciso reconhecer como irredutível o movimento pelo qual me empresto ao espetáculo, me junto a ele em um tipo de reconhecimento cego que precede a definição e a elaboração intelectual do sentido. [...] É por meu corpo que compreendo o outro, assim como é por meu corpo que percebo "coisas” (MERLEAU-PONTY, 2011, p. 252-253).
\end{abstract}

É necessário reaprender a ver o mundo a partir do corpo, contrapondo a visão de uma concepção restrita da ciência que percebe o corpo do outro como objeto para a obtenção de interesses próprios, reduzindo o ser humano à instrumentalização. A relação do sujeito com o mundo não pode ser limitada apenas pela percepção da ciência.

Nos capítulos sobre o mundo percebido em Fenomenologia da Percepção, MerleauPonty reforça a teoria da percepção fundada na experiência do sujeito encarnado, do sujeito que olha, sente e, nessa experiência do corpo fenomenal, reconhece o espaço como expressivo e simbólico (NÓBREGA, 2008, p. 142).

O mundo sensível é imbuído de saberes e conhecimentos; porém, desprezado pela ciência por analisá-lo pela ótica da razão. É na experiência sensível, através do corpo, que os discursos são produzidos (MERLEAU-PONTY, 2011).

Estes discursos são socialmente produzidos pelo papel que o corpo/corporeidade representa na cultura de determinada sociedade. As relações estabelecidas com os meios de produção de subsistência, economia e religiosidade são um dos diversos aspectos culturais que influenciam na construção da subjetividade do sujeito a partir do corpo/corporeidade (RIBERA, 2017). "Na perspectiva fenomenológica, a corporeidade é compreendida como a condição essencial do ser humano [...] um corpo vivo que cria linguagem e expressa-se pelo movimento com diferentes sentidos e significados" (NÓBREGA, 2019, p. 85). Por essa razão, as relações instituídas entre o sujeito consigo mesmo e o sujeito com os outros compõem o arcabouço do corpo/corporeidade para o esboço de si.

Segundo Merleau-Ponty (2011, p. 142), "Ser uma consciência, ou, antes, ser uma experiência, é comunicar interiormente com o mundo, como corpo e com os outros, ser com eles em lugar de estar ao lado deles". Este simples pensamento do autor, tendo em conta a corporeidade, já propiciaria uma forma diferenciada de trato com o fenômeno corpo/corporeidade.

Se levarmos as argumentações anteriores em consideração, fica claro atribuirmos à educação um valor pouco existente na atualidade. Para a fenomenologia, educação não está atrelada 
a mero domínio de conteúdo. Ela é a aprendizagem da cultura, não de uma cultura já estratificada, mas em constante movimento. Ela deve ser consagrada como:

[...] processo-projeto de humanização do sujeito, que não seria simplesmente objetopassivo, mas sujeito-ativo da história e da cultura. Neste sentido, mais do que um mero processo, a educação pretende ser um projeto de personalização dos sujeitos, da desalienação tanto individual como coletiva (REZENDE, 1990, p. 69).

Rezende (ibidem, p. 69) ainda afirma que "a existência humana é sempre ambígua, vivida na dialética da apropriação e da alienação”. O homem é constantemente ameaçado de viver sem perceber o(s) sentido(s) que sua vida está realmente tendo.

Percebemos, então, a dimensão do corpo/corporeidade segundo as referências anteriores, buscando uma inteligibilidade corpórea do ser na comunicação com o mundo. É importante o entendimento deste ponto para o próximo diálogo que traremos a seguir, a respeito do corpo do negro na perspectiva do outro - não negro, ao longo da história.

\section{Corpo/Corporeidade do negro}

\subsection{Corpo negro e a experiência no mundo sensivel}

Com a breve apresentação do corpo/corporeidade em Merleau-Ponty e demais autores referidos anteriormente, é possível perceber a proporção ocupada pelo corpo no mundo-vida. No entanto, no Brasil, o corpo do negro foi concebido e tratado de outra forma.

Pensando agora no corpo/corporeidade do negro, trazemos na pauta o terror da escravização na história brasileira, que traduziu a materialização do pensamento e do entendimento daqueles que a praticavam, sobretudo por não perceberem o ser humano de pele retinta como humano. Nesse período, o corpo negro era visto como ferramenta, instrumento de trabalho para o colonizador. "O escravo é visto pelo seu dono como um objeto, um acessório da terra, um animal humano, a objetivação de um capital; em suma, como um simples instrumento de produção" (CARDOSO, 1982, p. 59).

O racismo, desde a época da colonização do Brasil, naturalizou e normatizou o açoitamento, entre outras práticas de tortura, e a objetificação dos povos negros como moeda de troca através da compra e venda de pessoas, pelo simples fato de serem negros. Por isso, todos os argumentos e lógica existentes naquele período eram usados como justificativas pelas ações que praticavam (FREYRE, 2003). 
Os Sermões do Padre Antônio Vieira, da ordem dos jesuítas, ainda no Brasil colônia, trazem um pouco do entendimento da época acerca do negro. Bosi (1989; 2009) um estudioso dos sermões do Padre, analisa as contradições do eclesiástico em seus discursos religiosos validando o regime escravocrata. O corpo do negro assume um caráter de instrumento de trabalho, necessário à organização da colônia, sem o qual, acreditava a branquitude, seria impossível viverem.

No entanto, o pensamento dos jesuítas assumiu o caráter de normatização ao longo dos anos, como relatado por Freyre (2003, p. 291): “Ao escravo negro se obrigou aos trabalhos mais imundos na higiene doméstica e pública dos tempos coloniais. Um deles, o de carregar à cabeça, das casas para as praias, os barris de excremento vulgarmente conhecidos por tigres."

Toda a retórica e inteligência eram adotadas para validar os atos daqueles que usavam o corpo do negro como instrumento de trabalho, conforme aponta o autor: "Os negros e as pretas chamados de ganho serviram para tudo no Brasil: vender azeite-de-carrapato, bolo, cuscuz, manga, banana, carregar fardos, transportar água do chafariz às casas [...]” (ibidem p. 284). Em outros termos, todo o trabalho doméstico, no campo ou qualquer outra atividade braçal na colônia era destinada ao negro.

Outrora, o negro era usado para os prazeres numa relação objetal, como exemplifica Freyre ao falar como era a convivência dos marinheiros com as meninas negras de 10,12 anos: [...] "e toda essa superexcitação dos gigantes louros, bestiais, descarregava-se sobre molequinhas; e além da superexcitação, a sífilis; as doenças do mundo - das quatro partes do mundo; as podridões internacionais do sangue (ibidem, p. 285).

Mesmo diante de situações atrozes, a explicação anunciada pelo Padre Vieira era de que o corpo do negro, embora sentisse as vicissitudes da condição que estavam - escravizados - deveria ser suportada, pois suas almas seriam livres após a morte e como recompensa, seriam conduzidas aos céus (BOSI, 1989; 2009).

Desde que os negros chegaram ao Brasil as agressões e exploração do seu corpo foram normatizadas pelas leis vigentes e naturalizadas pelos colonizadores, classificando-os como se estivessem à parte da humanidade. E mesmo na atualidade, no século XXI, ainda existe o ranço dos mais de 300 anos de escravização no país. A sociedade foi alicerçada em uma cultura patriarcal onde a exploração da raça negra sempre foi comum e está emaranhado em todas as bases das relações sociais; é o chamado racismo estrutural.

O que queremos enfatizar, do ponto de vista teórico, é que o racismo, como processo histórico e político, cria as condições sociais para que, direta ou indiretamente, grupos racialmente identificados sejam discriminados de forma sistemática (ALMEIDA, 2020, p. 51). 
E como consequência, perpetuam-se os estigmas sobre o negro ao longo da história, como se a existência do povo negro tivesse começado a partir da escravização. Em outras palavras, uma ancestralidade massacrada e subjetividades construídas sob a égide da anulação do corpo/corporeidade do negro. O silenciamento usado de forma concreta com a mordaça nas bocas dos escravos foi transferida, na atualidade, pela negação da existência do negro como ser humano.

Isso negou-lhe a visão dos seus nos espaços de poder, nos brinquedos das crianças - não havia bonecas pretas -, nos personagens da tv - os atores negros representavam apenas trabalhos domésticos ou de escravos -, nos filmes do cinema, nas características do seu corpo - o cabelo crespo que tinha que ser alisado. E dessa forma, sua imagem foi descontruída e sua subjetividade fragmentada.

Então o esquema corporal, atacado em vários pontos, desmoronou, cedendo lugar a um esquema epidérmico racial. No movimento, não se tratava mais de um conhecimento de meu corpo na terceira pessoa, mas em tripla pessoa. [...] Eu existia em triplo: ocupava determinado lugar. Ia ao encontro do outro... e o outro, evanescente, hostil mas não opaco, transparente, ausente, desaparecia. A náusea... (FANON, 2008, p. 105).

A anulação dos elementos que remetem à construção de si, como o reconhecimento e validação do outro nas relações sociais, é o ponto fractal da questão que o autor faz menção. "No mundo branco, o homem de cor encontra dificuldades na elaboração de seu esquema corporal. $\mathrm{O}$ conhecimento do corpo é unicamente uma atividade de negação. É um conhecimento em terceira pessoa" (ibidem, p. 104).

O corpo/corporeidade das pessoas negras passa por essa dinâmica de falta de representação e silenciamento na sociedade colonizada diariamente no mundo-vida através do racismo. Essa realidade é citada por Almeida (2020) e revela as experiências cotidianas, inclusive do sistema educacional.

O racismo constitui todo um complexo imaginário social que a todo momento é reforçado pelos meios de comunicação, pela indústria cultural e pelo sistema educacional. $\mathrm{E}$ a escola reforça todas essas percepções ao representar um mundo em que negros e negras não têm muitas contribuições importantes para a história, literatura, ciência e afins, resumindo-se a comemorar a própria libertação graças a bondade de brancos conscientes (ALMEIDA, 2020, p. 65).

Uma vez segmento da sociedade organizada, a escola acaba por reproduzir igualmente o olhar a respeito do corpo negro, (de)formando a percepção dos educandos. No documento aprovado recentemente, regulando o currículo das escolas no país, a BNCC - Base Nacional Comum Curricular - a temática do povo negro aparece apenas em alguns itens das disciplinas de 
História e Geografia. Como a educação pode ignorar a história de um povo cuja população é a maioria? (BRASIL, 2018).

Escola, professores, rede mantenedora, currículo fazem parte de uma rede maior, que acaba por refletir o que já está posto na sociedade. A escola deveria ser um lugar de formação integral do ser humano, mas na prática não é isso o que ocorre de fato, por isso ela segue ensinando sem enxergar os corpos que a compõe.

Os dados do IBGE (2018) apontam, em todas as categorias investigadas, as disparidades por raça/cor no Brasil. No mercado de trabalho dos cargos gerenciais, 68,6\% destes são ocupados por brancos e $29,9 \%$, por pretos ou pardos. No quesito distribuição de renda e condições de moradia, apenas $15,4 \%$ das pessoas brancas estão abaixo da linha da pobreza, contra 32,9\% de pretos e pardos; no que se refere à educação, a taxa de analfabetismo dos pretos e pardos atinge o índice de $9,1 \%$, enquanto dos brancos é 3,9\% no total.

No item da representatividade política, dos deputados federais eleitos, os pretos e pardos correspondiam apenas a 24,4\%, enquanto brancos eram de 75,6\%. No que tange à taxa de homicídio, os números são alarmantes; $98,5 \%$ das mortes são de pretos e pardos. Isso mostra as características de uma sociedade com traços da colonização escravocrata, que desde a escravização até os dias atuais coloca o corpo preto com menor valor, inclusive a vida. A denúncia se torna ainda mais grave pelo fato de o Brasil possuir em sua maioria pretos e pardos (56\%). A quem pedir ajuda, se nas bancadas dos ministérios políticos a representatividade é mínima?

\footnotetext{
Se os negros vivem nas favelas porque não possuem meios para alugar ou comprar residência nas áreas habitáveis, por sua vez a falta de dinheiro resulta da discriminação no emprego. Se a falta de emprego é por causa de carência de preparo técnico e de instrução adequada, a falta desta aptidão se deve à ausência de recurso financeiro. Nesta teia, o afro-brasileiro se vê tolhido de todos os lados, prisioneiro de um círculo vicioso de discriminação [...] (NASCIMENTO, 2016, p. 75).
}

As políticas racistas incidem no alvo do que Merleau-Ponty havia percebido posteriormente; o corpo encarnado e a sua relação com o mundo. Atacar o corpo preto submetendo-o a práticas constantes de racismo, cotidianamente, afeta a sua subjetividade e a percepção de si no mundo; em outras palavras, a própria existência.

É importante também ressaltar que a experiência no mundo sensível remete às relações de poder socias que incidem sobre os corpos - e de forma mais incisiva, os corpos negros. São nos espaços sociais do mundo-vida que as experiências se dão, as relações de poder se estabelecem entre os sujeitos de acordo com as representações sociais instituídas; e é nesse contexto que o corpo 
preto se configura mais uma vez de forma negativa, pois o que está estabelecido na sociedade brasileira é o racismo estrutural.

O corpo preto é um corpo social construído a partir da colonização, em que as políticas de corpo arquitetaram, desde o período da escravização, um olhar sobre tal corpo que o açoita e penaliza - atualmente de forma sutil, mas não menos violenta. Nesse contexto, a penalidade por carregar um corpo preto incide sobre este, outro tipo de condenação. "O sofrimento físico, a dor do corpo não são mais elementos constitutivos da pena. O castigo passou de uma arte das sensações insuportáveis a uma economia dos direitos suspensos” (FOUCAULT, 2008, p. 14).

Segundo o autor, após a proibição dos suplícios, no final do século XVIII e início do século XIX, outras formas de poder sobre o corpo tornaram-se meticulosas e incisivas (FOUCAULT, 2021), tirando do corpo preto a liberdade de ser em sua completude. Se são nas instituições que o poder é exercido, são nelas também que o corpo preto atinge o ponto máximo de seu apagamento. Uma forma de matá-lo - não mais com os açoites, mas agora com a sua invisibilidade, supressão de direitos e menos valia nos cargos de emprego a que se propõe. O racismo impõe uma disciplina no corpo negro que o disseca, tirando dele apenas o serviço útil para a colonialidade.

O corpo humano entra numa maquinaria de poder que o esquadrinha, o desarticula e o recompõe. [...]. A disciplina fabrica assim corpos submissos e exercitados, corpos "dóceis". A disciplina aumenta as forças do corpo (em termos econômicos de utilidade) e diminui essas mesmas forças (em termos políticos de obediência) (FOUCAULT, 2008, p. 118).

O fenômeno citado pelo autor refere-se à dinâmica das instituições sobre os corpos e as possíveis relações estabelecidas entre os sujeitos. Porém, em um sistema onde prevalece o racismo estrutural, esse poder social sobre o corpo negro se torna mais evidente, afetando de forma sistemática a sua subjetividade ao longo dos anos.

\subsection{Corpo negro e o processo de subjetivação}

Pensando na proposta de Merleau-Ponty (2011) e as questões levantadas a respeito do corpo/corporeidade do negro, percebe-se a importância de destacar o que essa desconstrução acerca do corpo negro desencadeia na formação de si enquanto sujeito no processo de subjetivação.

Mesmo sabendo do seu valor enquanto humano e suas qualidades, o ser humano vive em sociedade e se constitui a partir das relações estabelecidas nela. Os processos políticos, sociais e históricos construídos são instituídos por ideologias que podem ser perceptíveis para alguns e para outros não. Porém, todos sofrem a sua influência, pois esta determina a forma como as situações serão estipuladas entre os sujeitos sociais. A ideologia é uma representação da realidade e não 
necessariamente a realidade em si; no entanto, é ela quem consolidará o pano de fundo dos atores sociais (ALMEIDA, 2020).

Partindo dessa premissa, incluímos então o corpo/corporeidade do negro, consciência encarnada agindo no mundo sensível (MERLEAU-PONTY, 2011). Mundo este onde as relações, permeadas pelas ideologias e representações sociais estão postas para desabilitá-lo de si, "o racismo como ideologia, molda o inconsciente" (ALMEIDA, 2020, p. 65).

Imagens, símbolos, discursos, representações o endereçam a tudo o que não diz respeito a si mesmo. Repetidamente, em todos os espaços sociais a mensagem passada é a mesma. Instituições, pessoas em situações de poder e que ditam regras sociais corroboram o mesmo discurso, ainda que não seja dito explicitamente. Nesse movimento, o negro elabora desde a tenra idade os elementos para perceber-se, sabendo intimamente que mesmo não concordando - aceita$\mathrm{o}$, pois todos os outros agentes envolvidos entendem que essa é a verdade posta, uma vez que não é questionada - afinal, sempre foi assim (ALMEIDA, 2020; FANON, 2008).

No cenário da sociedade colonizada, corpos negros possuem papeis pré-definidos, impondo-lhes performances que não coincidem consigo, sendo, no entanto, normatizado. O negro torna-se corpo/corporeidade racializada pelos processos subjetivos que são apreendidos pelas relações estabelecidas diariamente, como explica o autor:

\footnotetext{
Nossa relação com a vida social é mediada pela ideologia, ou seja, pelo imaginário que é reproduzido pelos meios de comunicação, pelo sistema educacional e pelo sistema de justiça em consonância com a realidade. Assim, uma pessoa não nasce branca ou negra, mas torna-se a partir do momento em que seu corpo e sua mente são conectados a toda uma rede de sentidos compartilhados coletivamente, cuja existência antecede a formação de sua consciência e de seus afetos (ALMEIDA, 2020, p. 67).
}

Conforme explica o autor, o racismo é uma construção social e molda o processo de construção das subjetividades dos corpos negros. Seguindo a mesma linha de pensamento, Merleau Ponty (2011, p. 485) conclui: "nossa relação com o social é, assim como nossa relação ao mundo, mais profunda que qualquer percepção explícita ou qualquer juízo".

Maria da Consolação Andre (2007) desenvolve em sua tese estudo investigando a respeito da construção da subjetividade dos afrodescendentes brasileiros. Nele, a autora percebe o sofrimento psíquico nas relações sociais devido à ideologia do branqueamento presente na sociedade, que nada mais é que uma outra faceta do racismo estrutural presente no país. Continuando, a autora entende "que a constituição da subjetividade ocorre na objetificação que é dada nos embates relacionais da vida social que são acontecimento da história da civilização" 
(ANDRE, 2007, p. 58). Sabendo que essa civilização é pautada pelo colonialismo e eurocentrismo, tornar-se evidente como essa subjetividade será consolidada.

Embora Maria da Consolação realize sua investigação a partir do materialismo histórico dialético e Merleau-Ponty (2011) desenvolva seus estudos compreendendo a constituição do corposujeito em sua relação com o mundo sensível pelos processos de produção de cultura, em ambos os estudos é possível perceber que a subjetividade - sobretudo do negro - será moldada, seja nas relações sociais ou no movimento intencional do corpo/corporeidade no mundo, dentro de uma realidade social colonizada e eurocêntrica - ou seja, a verdade posta e normalizada atualmente. E nesse contexto os encontros entre corporeidades dar-se-ão concedendo a possibilidade - ou não de existir o diálogo com o "nós".

\section{Quando o “eu” e o “outro” não quer dizer nós}

Diante do exposto sobre corpo/corporeidade em Merleau-Ponty e a dialética da colonização, ao referir-se ao corpo/corporeidade do negro, apontamos o quanto a existência para os negros torna-se imbuída de antagonismos e desconstruções diárias, sendo necessária a autoafirmação cotidiana diante da aspereza da sociedade colonizada do século XXI. Mesmo sabendo que o racismo tem várias faces, a realidade a qual o negro é exposto remete à sua corporeidade, conforme explica Fanon (2008), que era um africano que vivia na França:

O judeu só não é amado a partir do momento em que é detectado. Mas comigo tudo toma um aspecto novo. Nenhuma chance me é oferecida. Sou sobredeterminado pelo exterior. Não sou escravo da "ideia" que os outros fazem de mim, mas da minha aparição (FANON, 2008, p. 108).

Fanon denuncia o "apartheid" com o negro quando o "outro" - branco - o vê. O corpo preto já carrega na pele o conceito da própria existência e a forma como será interpretado, pela ótica do sujeito branco, antes mesmo de proferir qualquer palavra. Dentro da abordagem psicanalítica a constituição da subjetividade do sujeito negro é formatada por esse viés, como explica a Kilomba.

O sujeito negro torna-se então tela de projeção daquilo que o sujeito branco teme reconhecer sobre si mesmo. [...]. No mundo conceitual branco, o sujeito negro é identificado como o objeto "ruim", incorporando os aspectos que a sociedade branca tem reprimido e transformado em tabu [...] (KILOMBA, 2019, p. 37).

E dessa forma, como relata a autora, a composição do "nós" enquanto seres humanos se estabelece de forma incompleta, cindida, porque o "outro" - sujeito branco - não valida o corpo/corporeidade do negro em sua totalidade, observando-o sob o olhar vertical. 
Essa premissa de invalidação e negação produzido pelo racismo é relatado por um dos sujeitos entrevistados por Kilomba (2019). No diálogo, a mulher negra que estudava e morava na Alemanha confessou à amiga - branca - o incômodo de ser sempre a única negra nos espaços que frequentava, principalmente na universidade onde estudavam. Ela, por sua vez, afirmou que a amiga não era negra e nunca a tinha visto como tal. Nessa descrição a autora explica:

O que era visto de repente se torna invisível. [...] Essa repentina incapacidade de ver
"raça", uma vez que esta é mencionada por aquelas/es marcadas/os como
racializadas/os, parece se relacionar a um mecanismo de negação massivo, no qual a
negritude é apenas admitida na consciência em sua forma negativa. [...] Além disso, elas
também impedem o sujeito branco de ter de lidar com o desconfortável fato de que
diferenças existem e que essas diferenças surgem através de processos de discriminação
(KILOMBA, 2019, p. 146).

Essas experiências provocam ambivalência no sujeito negro, pois aquilo que o define ora é negado e ora é visto para o diferenciar dos demais e discriminá-lo. A possibilidade de formação do "nós" no espaço de igualdade permanece refutado. O psiquiatra e psicólogo Fanon (2008) continua o raciocínio:

No mundo branco, o homem de cor encontra dificuldades na elaboração de seu esquema corporal. O conhecimento do corpo é unicamente uma atividade de negação. É um conhecimento em terceira pessoa. Em torno do corpo reina uma atmosfera de incertezas (FANON, 2008, p. 104).

Ser negro é ocupar esse espaço do não-lugar em um momento e no outro, ocupar um subespaço, sendo visto pelo que não é, sendo socialmente subjugado pelo racismo estrutural da sociedade brasileira. Esse é o lugar de fala (RIBEIRO, 2019) do corpo/corporeidade do negro, “[...] a luta à qual o sujeito negro é submetido, uma luta para se identificar com o que se é, mas não como se é visto no mundo conceitual branco - uma ameaça” (KILOMBA, 2019, p. 153). Ser visto nas representações das mídias da TV e na sociedade não somente como o escravo, a empregada doméstica, o porteiro, o segurança, por exemplo; não que tenha algo de errado com essas profissões. Mas por que não em outros também como o médico, o juiz, a jornalista, entre outros? (RIBEIRO, 2019).

O corpo sendo consciência encarnada dialoga com outros corpos apreendendo o mundo pela percepção e sentidos, corpo político, histórico e socialmente demarcado. Corpo negro em busca de si - em sua relação com o outro e o mundo. 


\section{Considerações finais}

Ao analisar a abordagem do corpo/corporeidade em Merleau-Ponty (2011) percebemos a dimensão do humano e o seu diálogo com o mundo através do seu corpo. É por ele que a existência é significada.

É inegável as atrocidades realizadas pelos senhores dos engenhos com os escravos no Brasil colônia. Por essa razão, é necessário compreender que o corpo/corporeidade do negro foi desconstruído historicamente pelos infortúnios criados por aqueles que se percebiam como superiores. Negaram a humanidade do humano, o corpo/corporeidade do negro foi relegado e tratado como coisa.

E mesmo agora, no século XXI, os discursos a respeito do negro estão impregnados do mesmo ranço de tempos atrás. O racismo estrutural fundado na sociedade brasileira revela a forma como o corpo negro ainda é visto, pensado e tratado. "A viabilidade da reprodução sistêmica de práticas racistas está na organização política, econômica e jurídica da sociedade. O racismo se expressa concretamente como desigualdade política, econômica e jurídica” (ALMEIDA, 2020, p. $50)$.

O corpo negro ainda sente na pele os reflexos de séculos de abandono e tentativas de desumanizar o seu ser. Portanto, descontruir a ideologia de diferenças hierárquicas pela pigmentação da pele é um exercício contínuo. A percepção do corpo/corporeidade significa compreender o ser-no-mundo em sua totalidade, em constante busca de sentidos para a sua existência.

\section{Referências}

ALMEIDA, S. Racismo Estrutural. São Paulo: Editora Jandaia, 2020.

ANDRE, M. C. O ser negro: um estudo sobre a construção de subjetividades em afrodescendentes. 2007. 254 f. Tese (Doutorado em Psicologia) - Universidade de Brasília, Brasília.

BOSI, Alfredo. Vieira, ou a cruz da desigualdade. Novos Estudos Cebrap, São Paulo, n. 25, p. 28-9, out. 1989.

BOSI, Antônio Vieira, profeta e missionário: um estudo sobre a pseudomorfose e a contradição. Estudos Avançados. São Paulo, v. 23, n. 65, p. 247-270, 2009. Disponível em: https://doi.org/10.1590/S0103-40142009000100017 Acesso: 01 jul. 2021.

BRASIL. Ministério da Educação. Base Nacional Comum Curricular. Brasília, 2018. 
CARDOSO, Ciro Flamarion S. A Afro-América: A escravidão no novo mundo. São Paulo: Editora Brasiliense, 1982.

FANON, Frantz. Pele negra, máscaras brancas. Salvador: EDUFBA, 2008.

FOUCAULT, Michel. Vigiar e Punir: nascimento da prisão. 35ª ed. Petrópolis-RJ: Vozes, 2008.

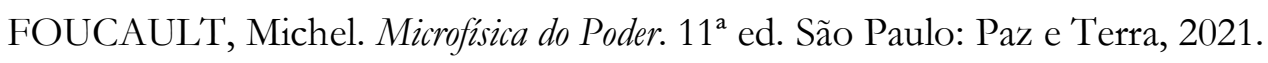

FREYRE, Gilberto. Casa-grande \& senz̧ala: formação da família brasileira sob o regime da economia patriarcal. $48^{\mathrm{a}}$ ed. rev. São Paulo: Global, 2003.

IBGE. Instituto Brasileiro de Geografia e Estatística (IBGE). Desigualdades Sociais por Cor ou Raça no Brasil. Estudos e Pesquisas. Informação Demográfica e Socioeconômica, n. 41.2018

KILOMBA, Grada. Memórias da Plantação - Episódios de racismo cotidiano. Trad. Jess Oliveira. $1^{\text {a }}$ ed. Rio de Janeiro: 2019.

MATHEUS, Eric. Compreender Merleau-Ponty. 2a ed., Rio de Janeiro: Vozes, 2011.

MERLEAU-PONTY, Maurice. Fenomenologia da percepção. $4^{a}$ ed., São Paulo: WMF Martins Fontes, 2011.

NASCIMENTO, Abdias do. O genocídio do negro brasileiro: processo de um racismo mascarado. São Paulo: Perspectiva, 2016.

NÓBREGA, Terezinha Petrúcia da. Corpo, percepção e conhecimento em Merleau-Ponty. Estudos de Psicologia. 2008. 13(2), 141-148. Disponível em:

https://www.scielo.br/pdf/epsic/v13n2/06.pdf Acesso 01 mar. 2021.

NÓBREGA, A Atitude Fenomenológica: o corpo-sujeito. In: NÓBREGA, Terezinha Petrúcia da. CAMINHA, Iraquitan de Oliveira. (Orgs). Merleau-Ponty e a Educação Física. São Paulo: Liber Ars, 2019. p. 69-91.

REZENDE, Antônio Muniz. Concepşão fenomenológica da educação. São Paulo: Cortez, 1990.

RIBEIRO, Djamila. Lugar de Fala. São Paulo: Pólen, 2019.

RIBERA, Jordi Planella. Corpo, Cultura e Educação. Tradução de Maria José Vicentini Jorente, Natalia Nakano, Lais Alpi Landim. São Paulo: Cultura Acadêmica, 2017. 